\title{
The Impact of the Amendment of the Korean National Health Insurance Reimbursement Criteria for Anti-tumor Necrosis Factor- $\alpha$ Agents on Treatment Pattern, Clinical Response and Persistence in Patients With Rheumatoid Arthritis
}

\author{
Yunkyung Kim, M.D. ${ }^{1}$, Geun-Tae Kim, M.D., Ph.D. ${ }^{1}$, Young Sun Suh, M.D., Ph.D. ${ }^{2}$, Hyun-Ok Kim, M.D., Ph.D. ${ }^{2}$, \\ Han-Na Lee, M.D. ${ }^{3,4}$, Seung-Geun Lee, M.D., Ph.D. ${ }^{3,4}$ \\ ${ }^{1}$ Division of Rheumatology, Department of Internal Medicine, Kosin University College of Medicine, Busan, ${ }^{2}$ Division of Rheumatology, \\ Department of Internal Medicine, Gyeongsang National University School of Medicine, Gyeongsang National University Changwon Hospital, \\ Changwon, ${ }^{3}$ Division of Rheumatology, Department of Internal Medicine, Pusan National University Hospital, Pusan National University School \\ of Medicine, ${ }^{4}$ Biomedical Research Institute, Pusan National University Hospital, Busan, Korea
}

\begin{abstract}
Objective. To investigate the impact of the amendment of the Korean National Health Insurance (KNHI) reimbursement criteria for anti-tumor necrosis factor- $\alpha$ (TNF- $\alpha$ ) agents based on from conventional clinical and laboratory measurements to disease activity score of 28 joints (DAS28) on treatment pattern, clinical response, and persistence rate in patients with rheumatoid arthritis (RA). Methods. This multicenter retrospective cohort study evaluated 148 RA patients eligible for the initiation of anti-TNF- $\alpha$ agents as the first-line biologics by either the past $(n=95)$ or current $(n=53)$ KNHI reimbursement criteria. Persistence was defined as the duration between the initiation and discontinuation of anti-TNF $\alpha$ agents. Results. In total, $106(71.6 \%), 35$ $(23.6 \%)$, and $7(4.7 \%)$ RA patients started treatment with adalimumab, etanercept, and infliximab, respectively. RA patients who received anti-TNF- $\alpha$ agents under the current reimbursement criteria had a significantly lower mean DAS28-erythrocyte sedimentation rate (ESR) $(6.02$ vs. $6.95, \mathrm{p}<0.001)$ and daily prednisolone-equivalent glucocorticoid dose $(4.51 \mathrm{vs.} 6.17 \mathrm{mg}$, $\mathrm{p}<0.001)$ than those who received anti-TNF- $\alpha$ agents under the past reimbursement criteria. No significant differences in the 1 -year remission rate defined by DAS28-ESR $<2.6(17.9 \%$ vs. 30.2\%, $p=0.085)$ and the persistence rate $(p=0.703)$ between the past and current reimbursement criteria was observed. Conclusion. Our data suggest that less active RA patients can receive reimbursement for anti-TNF- $\alpha$ agents under the current criteria, and the amendment of the KNHI reimbursement criteria may improve access to anti-TNF- $\alpha$ agents without affecting the treatment response and persistence rate. (J Rheum Dis 2020;27:159-167)
\end{abstract}

Key Words. Rheumatoid arthritis, Tumor necrosis factor-alpha, Health insurance, Health care costs, Treatment outcome

\section{INTRODUCTION}

Anti-tumor necrosis factor- $\alpha$ (TNF- $\alpha$ ) agents were historically the first biologics applied in clinical trials and clinical practice for patients with rheumatoid arthritis (RA). The introduction of anti-TNF- $\alpha$ agents into the therapeutic armamentarium has revolutionized the RA management due to their high efficacy in reducing disease activity, delaying progressive joint damage, and pre- serving functional capacity [1]. Since the approval of anti-TNF- $\alpha$ agents in the mid-1990, their use has dramatically expand worldwide [1]. In general, the initiation of anti-TNF- $\alpha$ agents is recommended if the disease activity remains moderate to high despite treatment with the first conventional disease modifying anti-rheumatic drugs (cDMARDs) according to international guidelines, such as the American College of Rheumatology (ACR) and European League against Rheumatism (EULAR) [2,3].

\footnotetext{
Received : February 20, 2020, Revised : March 16, 2020, Accepted : March 22, 2020

Corresponding to : Seung-Geun Lee (iD http://orcid.org/0000-0002-5205-3978

Division of Rheumatology, Department of Internal Medicine, Pusan National University Hospital, Pusan National University School of Medicine, 179 Gudeok-ro, Seo-gu, Busan 49241, Korea. E-mail : sglee@pusan.ac.kr
}

Copyright (c) 2020 by The Korean College of Rheumatology.

This is an Open Access article, which permits unrestricted non-commerical use, distribution, and reproduction in any medium, provided the original work is properly cited. 
Considering the progressive disease course and consequently significant clinical burden of RA, timely and appropriate treatment with anti-TNF- $\alpha$ agents is crucial. However, patients with RA often experience substantial barriers to access to anti-TNF- $\alpha$ agents because of their high cost, potential adverse events, and parenteral administration as well as lack of specialized healthcare professionals [4]. In particular, low economic status is one of the major predisposing factors for undertreatment with anti-TNF- $\alpha$ agents [5].

To overcome this issue, most countries worldwide have their own health insurance reimbursement criteria for anti-TNF- $\alpha$ agents. Given that the extent of anti-TNF- $\alpha$ agents use was greatly dependent on the health insurance coverage, health regulatory agencies should establish appropriate reimbursement criteria. In South Korea, it is mandatory for all citizens to have the Korean National Health Insurance (KNHI) by law, and all anti-TNF- $\alpha$ agents are only reimbursed under the KHNI system. In 2006, the KHNI reimbursement criteria for anti-TNF- $\alpha$ agents based on conventional clinical and laboratory measurements such as the number of joint involvement, levels of acute phase reactants, and duration of morning stiffness were introduced. However, these criteria have been criticized by a number of studies to be too strict and less objective [6-8]. Thus, the past KNHI reimbursement criteria were revised according to the disease activity score, assessed using the 28-joint count for swelling and tenderness (DAS28), by the Ministry of Health and Welfare of South Korea in January 2014. However, only few studies directly compared the differences in the access to anti-TNF- $\alpha$ agents and clinical outcomes in patients with RA between the past and current KNHI reimbursement criteria [9]. Therefore, in the present study, we aimed to investigate the impact of the recent amendment of the KNHI reimbursement criteria on the treatment pattern, clinical response, and persistence rate in patients with RA in clinical practice.

\section{MATERIALS AND METHODS}

\section{Study design and patients}

This is a retrospective cohort study performed at three university-affiliated rheumatology centers in South Korea. We evaluated 148 RA patients aged between 20 and 85 years who were newly initiated anti-TNF- $\alpha$ agents as first-line biologic treatment due to inadequate response to methotrexate (MTX) and/or cDMARDs between January
2007 and September 2018 through a medical record review. RA was diagnosed according to the 1987 ACR (formerly American Rheumatism Association) revised classification criteria [10] or the 2010 ACR/EULAR classification criteria [11]. Anti-TNF- $\alpha$ agents available in the three centers during the study period, which were investigated in this study, were subcutaneous adalimumab, subcutaneous etanercept, and intravenous infliximab. The index date was defined as the date of the first prescription of anti-TNF- $\alpha$ agents during the study period. The exclusion criteria included RA patients aged $<20$ years use of any biologic agents before the index date, use of biologic agents other than anti-TNF- $\alpha$ agents, and other accompanying autoimmune diseases except for secondary Sjögren's syndrome. This study was approved by the Institutional Review Boards of Kosin University Gospel Hospital (IRB no. 018-09-029), Gyeongsang National University Changwon Hospital (IRB no. 201902-022), and Pusan National University Hospital (IRB no. 1810-003-071), which waived the requirement for obtaining patients' informed consent due to the study's retrospective nature.

\section{Clinical assessments}

The following demographic and clinical data at the index date were collected: age, sex, disease duration, erythrocyte sedimentation rate (ESR), C-reactive protein (CRP), rheumatoid factor (RF), anti-cyclic citrullinated peptide (CCP) antibody, DAS28-ESR, DAS28-CRP, type of anti-TNF- $\alpha$ agents, and medications including cDMARD, glucocorticoids (GCs), and daily prednisolone-equivalent GC dose. Disease duration was defined as the time from the date of diagnosis to the index date. DAS28-ESR was calculated as follows: $[0.56 \times \sqrt{ }$ (tender joint count 28) $]+[0.28 \times \sqrt{ }$ (swolle joint count 28$)]+$ $[0.70 \times \ln \mathrm{ESR}]+[0.0014 \times$ visual analog scale score $]$ and DAS28-CRP was calculated as $[0.56 \times \sqrt{ }$ (tender joint count 28$)]+[0.28 \times \sqrt{ }($ swolle joint count 28$)]+[0.36 \times$ $\ln (C R P+1)]+[0.0014 \times$ visual analog scale score $]+0.96$ $[12,13]$. Seropositve RA was defined as a positive result for RF or anti-CCP antibody.

At the 1-year follow-up, data regarding DAS28-ESR, DAS28-CRP, remission rate, and treatment response were obtained. Remission was defined as DAS28-ESR $<2$.6. Treatment response to anti-TNF- $\alpha$ agents was determined according to the EULAR response criteria, which was classified as good, moderate, or non-response [14]. Good response was defined as a DAS28-ESR im- 
provement of $>1.2$ and DAS28-ESR of $\leq 3.2$, and non-response was defined as a DAS28-ESR improvement of $<0.6$ or between 0.6 and 1.2 with DAS28-ESR of $>5.1$ at the 1-year follow-up [14]. The other values were classified as a moderate response [14].

Persistence was defined as the duration from the index date to the first discontinuation of anti-TNF- $\alpha$ agents; switch to another biologic agents including other anti-TNF- $\alpha$ agents, tocilizumab, abatacept, rituximab, tofacitinib, or baricitinib; or the end of the study period (September 2019). If the interruption of an anti-TNF- $\alpha$ agent (permissible gap) was prolonged for $>90$ days, it was considered as discontinuation [15]. The causes of discontinuation were categorized into lack of efficacy, adverse events, poor health literacy, pregnancy, patient's preference, cost, and unknown based on medical records. "Poor health literacy" indicates withdrawal of anti-TNF$\alpha$ agents because of the lack of unawareness of the significance and requirements of the regular use of these drugs, whereas "cost" was defined as discontinuation of anti-TNF- $\alpha$ agents due to the patients' economic reasons $[16,17]$.

The past and current KNHI reimburse criteria for the initiation and maintenance of anti-TNF- $\alpha$ agents are summarized in Table 1. If the maintenance criteria are met after 3 months (the past criteria) or 6 months (the current criteria) of using the anti-TNF- $\alpha$ agents, these drugs can be reimbursed for an additional of 6 months. If the maintenance criteria are not satisfied or serious adverse events occur, anti-TNF- $\alpha$ agents should be discontinued or switched to another anti-TNF- $\alpha$ agents or biologics under both the past and current KNHI reimbursement systems. The primary interest of this study was to compare the clinical characteristics and outcome such as treatment response at 1-year follow-up and persistence rate according to the past and current $\mathrm{KNHI}$ reimbursement criteria, as mentioned above.

\section{Statistical analyses}

All values are expressed as mean \pm standard deviation or median (interquartile range) for continuous variables as appropriate, and as numbers (percentages) for categorical variables. Clinical data of the study population were compared using the Student t-test or Mann-Whitney U-test for continuous variables and the chi-square test for categorical variables, as appropriate. The drug persistence to anti-TNF- $\alpha$ agents was calculated using the Kaplan-Meier survival curve, and the comparison of drug persistence according to the past and current KNHI reimbursement criteria was analyzed by the log-rank test. All statistical analyses were carried out using SPSS 18.0 for Windows (IBM Co., Armonk, NY, USA) and STATA

Table 1. Detailed information regarding the past and current Korean National Health Insurance (KNHI) reimbursement criteria

\begin{tabular}{|c|c|c|}
\hline Items & Past KNHI criteria & Current $\mathrm{KNHI}$ criteria \\
\hline \multirow[t]{4}{*}{$\begin{array}{l}\text { Requirement to start } \\
\text { anti-TNF- } \alpha \text { agents }\end{array}$} & $\begin{array}{l}\text { Met the } 1987 \text { to the } 1987 \text { American Society of } \\
\text { Rheumatology diagnostic criteria }\end{array}$ & $\begin{array}{l}\text { Met the } 2010 \text { American College of } \\
\text { Rheumatology/European League against } \\
\text { Rheumatism classification criteria }\end{array}$ \\
\hline & $\mathrm{ESR}>28 \mathrm{~mm} / \mathrm{hr}$ or $\mathrm{CRP}>2.0 \mathrm{mg} / \mathrm{dL}$ & $\begin{array}{l}\text { DAS-28 }>5.1 \text { or } 3.2 \leq \text { DAS- } 28 \leq 5.1 \text { with } \\
\text { radiographic progression }\end{array}$ \\
\hline & Morning stiffness $\geq 45 \mathrm{~min}$ & $\begin{array}{l}\text { cDMARDs } \geq 2 \text { including MTX and } 3 \text { months/each } \\
\text { CDMARD }\end{array}$ \\
\hline & $\begin{array}{l}\text { Active joint count } \geq 20 \text { or } \geq 6 \text { including } \geq 4 \text { large } \\
\text { joints in case of } \geq 4 \text { large joints involved } \\
\text { cDMARDs } \geq 2 \text { including MTX and } 3 \text { months/each } \\
\text { cDMARD }\end{array}$ & \\
\hline \multirow[t]{2}{*}{$\begin{array}{l}\text { Criteria to maintain } \\
\text { anti-TNF- } \alpha \text { agents }\end{array}$} & $\begin{array}{l}\text { ESR ( } \leq 28 \mathrm{~mm} / \mathrm{hr} \text { or improvement } \geq 20 \%) \text { or CRP } \\
(\leq 2.0 \mathrm{mg} / \mathrm{dL} \text { or improvement } \geq 20 \%) \text { after } 3 \\
\text { months }\end{array}$ & \\
\hline & $\begin{array}{l}\text { Active joint count (tender \& swollen) } \leq 50 \% \text { after } \\
3 \text { months }\end{array}$ & Improvement of DAS-28 $\geq 1.2$ after 6 months \\
\hline
\end{tabular}

TNF- $\alpha$ : tumor necrosis factor-alpha, ESR: erythrocyte sedimentation rate, CRP: c-reactive protein, DAS-28: disease activity score using the 28-joint count for swelling and tenderness, cDMARDs: conventional disease modifying anti-rheumatic drugs, MTX: methotrexate. 
version 15.0 for Windows (StataCorp LP, College Station, TX, USA), and $p<0.05$ was considered statistical significance.

\section{RESULTS}

The baseline clinical characteristics of the 148 patients with RA who started anti-TNF- $\alpha$ agents from 2007 to 2018 are shown in Table 2. Adalimumab ( $\mathrm{n}=106,71.6 \%)$ was the most commonly prescribed anti-TNF- $\alpha$ agents in RA patients, followed by etanercept $(n=35,23.6 \%)$ and infliximab $(n=7,4.7 \%)$. Ninety-four $(63.5 \%)$ and 54 (36.5\%) patients with RA started anti-TNF- $\alpha$ agents under the past and current KNHI reimbursement criteria, respectively. No significant differences in age, frequency of female sex, seropositive RA, and GC users, and number of previous cDMARDs between the past and current
KNHI criteria were observed. The mean DAS28-ESR and DAS28-CRP in RA patients who received anti-TNF- $\alpha$ agents under the current $\mathrm{KNHI}$ criteria were significantly lower than those who received anti-TNF- $\alpha$ agents under the past KNHI criteria $(6.02 \pm 0.71$ vs. $6.95 \pm 0.98, \mathrm{p}<$ 0.001 and $5.34 \pm 0.66$ vs. $6.15 \pm 1.05, \mathrm{p}<0.001$, respectively). In addition, patients receiving anti-TNF- $\alpha$ agents according to the current $\mathrm{KNHI}$ criteria had a significantly lower TJC, SJC, and daily GC dose than those receiving anti-TNF- $\alpha$ agents according to the past KNHI criteria. Serum ESR levels in the past KNHI criteria tended to be higher than that in the current $\mathrm{KNHI}$ criteria, whereas no significant difference in serum CRP levels were found between the two groups. Disease duration did not differ significantly between the past and current KNHI criteria.

The flow diagram of the current study is presented in Figure 1. Data regarding the 1-year treatment response to

Table 2. Comparisons of baseline clinical characteristics according to the past and current Korean National Health Insurance (KNHI) reimbursement criteria for anti-TNF- $\alpha$ agents

\begin{tabular}{|c|c|c|c|c|}
\hline Variable & $\begin{array}{l}\text { RA patients } \\
\quad(n=148)\end{array}$ & $\begin{array}{l}\text { Past KNHI criteria } \\
\qquad(\mathrm{n}=95)\end{array}$ & $\begin{array}{l}\text { Current KNHI criteria } \\
\qquad(n=53)\end{array}$ & $p$-value \\
\hline Age $(y r)$ & $47.9 \pm 12.0$ & $47.1 \pm 12.4$ & $49.5 \pm 11.2$ & 0.252 \\
\hline Sex, female & $132(89.2)$ & $85(89.5)$ & $47(88.7)$ & 0.881 \\
\hline Disease duration (mo) & $13(4 \sim 39)$ & $11(5.5 \sim 35.75)$ & $17(4 \sim 40.5)$ & 0.271 \\
\hline Seropositive RA* & $146(98.6)$ & $90(96.8)$ & $50(94.3)$ & 0.668 \\
\hline GCs user & $140(95.9)$ & $90(95.7)$ & $50(96.2)$ & 0.905 \\
\hline Daily GCs dose (mg) & $5.57 \pm 2.73$ & $6.17 \pm 2.76$ & $4.51 \pm 2.35$ & $<0.001$ \\
\hline Number of previous cDMARDs & $2(2 \sim 3)$ & $2(2 \sim 3)$ & $2(2 \sim 3)$ & 0.096 \\
\hline \multicolumn{5}{|l|}{ Concurrent cDMARDs } \\
\hline MTX & $136(91.9)$ & $90(94.7)$ & $46(86.8)$ & 0.09 \\
\hline $\mathrm{HCQ}$ & $8(5.4)$ & $5(5.3)$ & $3(5.7)$ & 0.918 \\
\hline SSZ & $12(8.1)$ & $5(5.3)$ & $7(13.2)$ & 0.09 \\
\hline LEF & $2(1.4)$ & $1(1.1)$ & $1(1.9)$ & 0.673 \\
\hline TAC & $1(0.7)$ & $1(1.1)$ & $0(0)$ & 1 \\
\hline \multicolumn{5}{|l|}{ Anti-TNF- $\alpha$ agents } \\
\hline Adalimumab & $106(71.6)$ & $70(73.7)$ & $36(67.9)$ & 0.75 \\
\hline Etanercept & $35(23.6)$ & $21(22.3)$ & $14(25.9)$ & \\
\hline Infliximab & $7(4.7)$ & $4(4.3)$ & $3(4.7)$ & \\
\hline DAS28-ESR & $6.61 \pm 0.99$ & $6.95 \pm 0.98$ & $6.02 \pm 0.71$ & $<0.001$ \\
\hline DAS28-CRP & $5.86 \pm 1$ & $6.15 \pm 1.05$ & $5.34 \pm 0.66$ & $<0.001$ \\
\hline TJC & $12(7 \sim 18)$ & $16(9.8 \sim 20)$ & $8(6 \sim 10.5)$ & $<0.001$ \\
\hline $\mathrm{SJC}$ & $6(10 \sim 18)$ & $16(9.5 \sim 19.3)$ & $7(4 \sim 8.5)$ & $<0.001$ \\
\hline $\mathrm{ESR}(\mathrm{mm} / \mathrm{hr})$ & $54(34 \sim 74)$ & $58(37 \sim 78)$ & $44(28 \sim 74)$ & 0.078 \\
\hline CRP (mg/dL) & $1.95(0.72 \sim 4.11)$ & $1.97(0.88 \sim 4)$ & $1.92(0.64 \sim 4.23)$ & 0.437 \\
\hline
\end{tabular}

Values are presented as mean \pm standard deviation, number (\%), or median (interquartile range). TNF- $\alpha$ : tumor necrosis factor-alpha, RA: rheumatoid arthritis, GCs: glucocorticoids, cDMARDs: conventional disease modifying anti-rheumatic drugs, MTX: methotrexate, HCQ: hydroxychloroquine, SSZ: sulfasalazine, LEF: leflunomide, TAC: tacrolimus, DAS-28: disease activity score using the 28-joint count for swelling and tenderness, ESR: erythrocyte sedimentation rate, CRP: C-reactive protein, TJC: tenderness joint count, SJC: swollen joint count. *Seropositive RA was defined as rheumatoid arthritis with positive rheumatoid factor or anti-cyclic citrullinated peptide antibody. 
anti-TNF- $\alpha$ agents were available in 51 and 35 patients under the past and current $\mathrm{KNHI}$ reimbursement criteria, respectively. The remission rate at 1-year follow-up in RA patients treated with anti-TNF- $\alpha$ agents under the past KNHI reimbursement criteria was numerically lower than that under the past criteria, but it did not reach statistical significance $(17.9 \%$ vs. $30.2 \%, p=0.085)$, as shown in Table 3. In addition, no significant difference in the frequency of moderate-to-good EULAR response between the two groups ( $51.6 \%$ vs. $66 \%, \mathrm{p}=0.119)$. Mean DAS28ESR, and DAS28-CRP at 1-year follow-up was found be- tween the two groups, but the median CRP levels in RA patients treated with anti-TNF- $\alpha$ agents under the past criteria was significantly lower than that under the past criteria (Table 3).

During the study period, 87 (58.8\%) patients with RA discontinued anti-TNF- $\alpha$ agents. The most common cause of discontinuation was lack of efficacy (65.5\%), followed by adverse events (13.8\%) and poor health literacy $(6.9 \%)$ (Table 4$)$. There was no significant difference in the frequency of causes of anti-TNF- $\alpha$ agent discontinuation between the past and current KNHI criteria (Table 4).

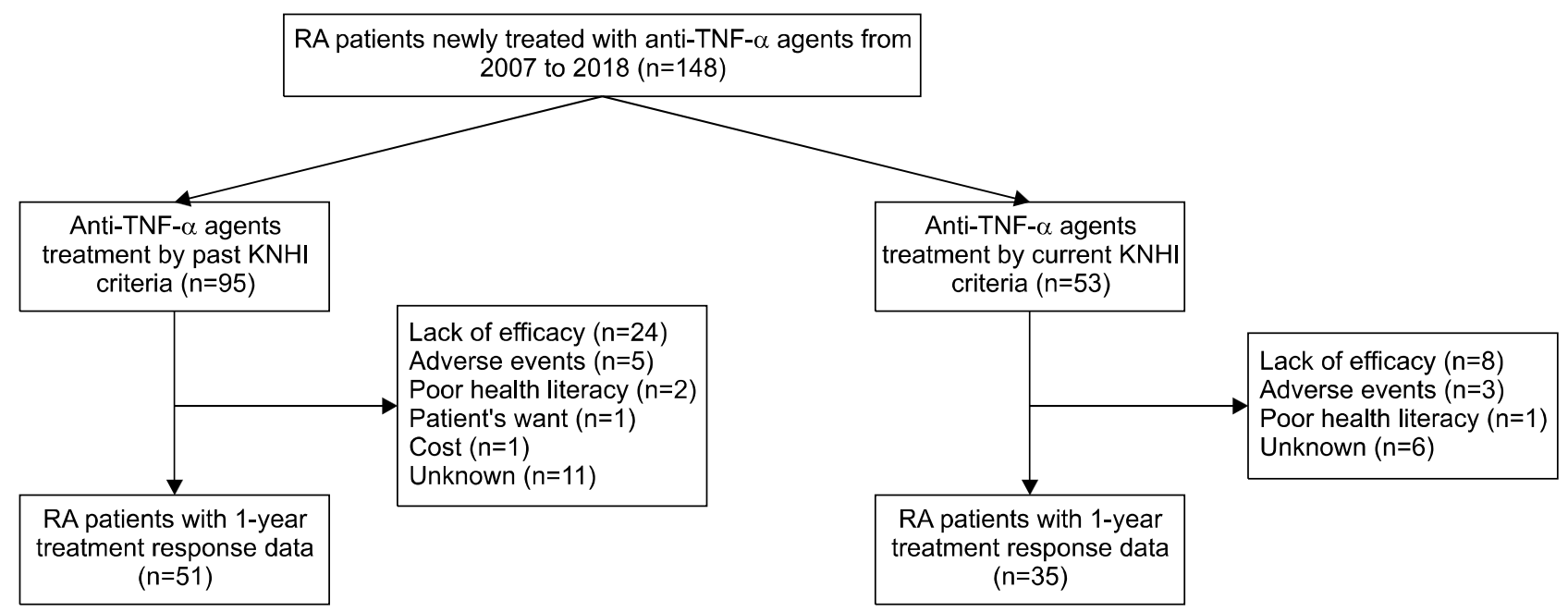

Figure 1. The flow diagram of the current study. RA: rheumatoid arthritis, TNF- $\alpha$ : tumor necrosis factor-alpha, KNHI: Korean National Health Insurance.

Table 3. Comparisons of 1-year clinical outcome in patients with rheumatoid arthritis receiving for anti-TNF- $\alpha$ agents according to the to the past and current Korean National Health Insurance $(\mathrm{KNHI})$ reimbursement criteria

\begin{tabular}{|c|c|c|c|c|}
\hline Variable & $\begin{array}{l}\text { RA patients } \\
(\mathrm{n}=148)\end{array}$ & $\begin{array}{l}\text { Past KNHI criteria } \\
\qquad(\mathrm{n}=95)\end{array}$ & $\begin{array}{l}\text { Current KNHI criteria } \\
\qquad(\mathrm{n}=53)\end{array}$ & p-value \\
\hline $\begin{array}{l}\text { RA patients with 1-year treatment } \\
\text { response data }\end{array}$ & $86(58.1)$ & $51(53.7)$ & $35(66)$ & 0.167 \\
\hline Remission* & $33(22.3)$ & $17(17.9)$ & $16(30.2)$ & 0.085 \\
\hline \multicolumn{5}{|l|}{ EULAR response } \\
\hline Moderate to good response & $84(56.8)$ & $49(51.6)$ & $35(66)$ & 0.119 \\
\hline No response & $2(1.4)$ & $2(2.1)$ & $0(0)$ & \\
\hline DAS28-ESR & $2.89 \pm 0.96$ & $2.97 \pm 1.09$ & $2.77 \pm 0.72$ & 0.348 \\
\hline DAS28-CRP & $2.31 \pm 0.87$ & $2.36 \pm 1.04$ & $2.23 \pm 0.54$ & 0.44 \\
\hline TJC & $1(0 \sim 2)$ & $1(0 \sim 2)$ & $0(0 \sim 1)$ & 0.243 \\
\hline SJC & $1(0 \sim 2)$ & $1(0 \sim 2)$ & $1(0 \sim 2)$ & 0.514 \\
\hline $\mathrm{ESR}(\mathrm{mm} / \mathrm{hr})$ & $21(11 \sim 35)$ & $22(11.25 \sim 37.5)$ & $17(9 \sim 30)$ & 0.092 \\
\hline $\mathrm{CRP}(\mathrm{mg} / \mathrm{dL})$ & $0.14(0.04 \sim 0.66)$ & $0.24(0.05 \sim 1.03)$ & $0.09(0.03 \sim 0.4)$ & 0.046 \\
\hline
\end{tabular}

Values are presented as number (\%), mean \pm standard deviation, or median (interquartile range). TNF- $\alpha$ : tumor necrosis factoralpha, RA: rheumatoid arthritis, EULAR: the European League against Rheumatism, DAS-28: disease activity score using the 28-joint count for swelling and tenderness, ESR: erythrocyte sedimentation rate, CRP: C-reactive protein, TJC: tender joint count, SJC: swollen joint count. * Remission was defined as DAS28-ESR less than 2.6. 
Yunkyung Kim et al.

Table 4. Comparisons of cause of discontinuation in patients with rheumatoid arthritis receiving for anti-TNF- $\alpha$ agents according to the to the past and current Korean National Health Insurance reimbursement criteria

\begin{tabular}{lcccc}
\hline \hline \multicolumn{1}{c}{ Variable } & $\begin{array}{c}\text { RA patients } \\
(\mathrm{n}=87)\end{array}$ & $\begin{array}{c}\text { Past criteria } \\
(\mathrm{n}=62)\end{array}$ & $\begin{array}{c}\text { Current criteria } \\
(\mathrm{n}=25)\end{array}$ & p-value \\
\hline Lack of efficacy & $57(65.5)$ & $41(66.1)$ & $16(64)$ & 0.913 \\
Adverse events & $12(13.8)$ & $9(14.5)$ & $3(12)$ & \\
Poor health literacy & $6(6.9)$ & $4(6.5)$ & $2(8)$ & \\
Pregnancy & $4(4.6)$ & $2(3.2)$ & $1(8)$ & \\
Patient's want & $2(2.3)$ & $1(1.6)$ & $0(0)$ & \\
Cost & $1(1.1)$ & $1(1.6)$ & $1(4)$ & \\
Unknown & $5(5.7)$ & $4(6.5)$ & & \\
\hline
\end{tabular}

Values are presented as number (\%). TNF- $\alpha$ : tumor necrosis factor-alpha, RA: rheumatoid arthritis.

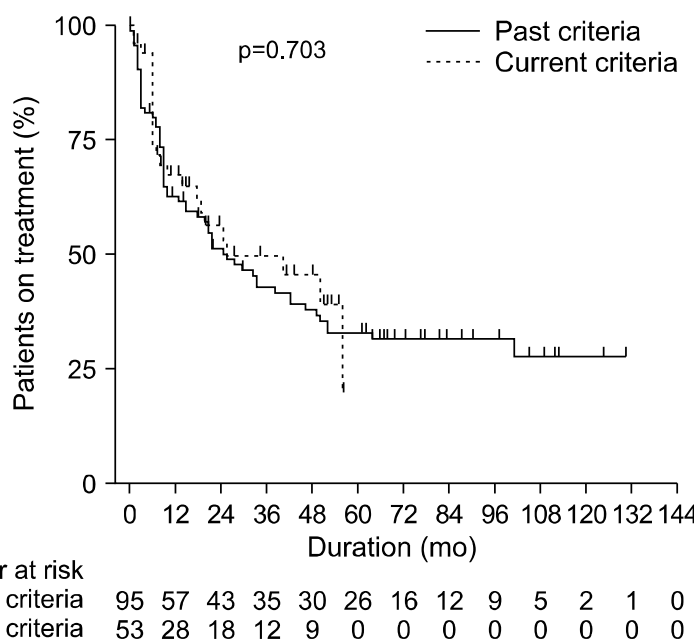

Figure 2. Comparison of persistence of anti-TNF- $\alpha$ agents in patient with rheumatoid arthritis under the past and current Korean National Health Insurance reimbursement criteria. TNF- $\alpha$ : tumor necrosis factor-alpha.

The 1- and 5-year persistent rates of anti-TNF- $\alpha$ agents in RA patients was $64.3 \%$ (95\% confidence interval [95\% $\mathrm{CI}]=55.8 \% \sim 71.5 \%)$ and $33.3 \%(95 \% \mathrm{CI}=24.7 \% \sim 42 \%)$, respectively, and the median time to anti-TNF- $\alpha$ agents withdrawal was 26 months (95\% CI=15.5 36.5) (Supplementary Figure 1). There was no significant difference in the persistent rate of anti-TNF- $\alpha$ agents according to the past and current KNHI reimbursement criteria ( $p=0.703$, Figure 2 ). In addition, cause specific persistent rate of anti-TNF- $\alpha$ agents did not differ significantly between the past and current reimbursement criteria (data not shown).

\section{DISCUSSION}

To the best of our knowledge, this is the first study to investigate the impact of the amendment of the $\mathrm{KNHI}$ re- imbursement criteria for anti-TNF- $\alpha$ agents based on from the conventional clinical and laboratory measurements to the composite disease activity index such as DAS28 on the treatment patterns and outcomes in real clinical practice. Patients with RA who started anti-TNF$\alpha$ agents under the current reimbursement criteria had significantly lower baseline disease activities and daily prednisolone-equivalent GC dose than those who started anti-TNF- $\alpha$ agents under the past reimbursement criteria, indicating that less active RA patients can receive reimbursement for anti-TNF- $\alpha$ agents under the current criteria. This notion suggests that more patients may benefit from the DAS28-based current reimbursement criteria, and the amendment of KNHI reimbursement criteria may allow easier use of anti-TNF- $\alpha$ agents. However, our data showed that the amendment of the reimbursement criteria did not improve the treatment response and persistence rate of anti-TNF- $\alpha$ agents in RA patients.

It is utmost important to establish appropriate reimbursement policies for the access to anti-TNF- $\alpha$ therapy in patients with RA, because treatment costs have been recognized as significant concerns for use of these medications $[18,19]$. Previous studies reported that there was a substantial worldwide variability in the utilization of anti-TNF- $\alpha$ agents in patients with RA according to the different criteria in different regions [20-23] and countries with lower income tended to have stricter eligibility criteria leading to poorer access to these medications [20]. Only approximately half of the RA patients eligible for anti-TNF- $\alpha$ agents in accordance with EULAR recommendations can meet the national reimbursement criteria in European countries [22], suggesting that a significant proportion of patients are less likely to receive adequate treatment in real practice. As pointed by Hur et al. [24], the past KNHI reimbursement criteria are more 
stringent compared with the ACR guidelines primarily due to the requirement of active joint count $\geq 20$ or $\geq 6$ including $\geq 4$ large joints in case of involvement of $\geq 4$ large joints. Our result suggests that the current $\mathrm{KNHI}$ reimbursement criteria based on DAS28 would be less strict in terms of the initiation of anti-TNF- $\alpha$ agents than the past criteria based on clinical and laboratory indices. Thus, we speculated that the amendment of the reimbursement criteria would be highly desirable in that more RA patients can receive optimal treatment and contribute to improve the affordability of the anti-TNF- $\alpha$ therapy.

Treatment to target (T2T) and adjusting therapy according to the validated composite measure of disease activity, such as the DAS and EULAR response criteria, are recognized as a standard strategy in RA management to reach optimal clinical outcomes [25]. Regarding the initiation and maintenance of anti-TNF- $\alpha$ agents, the current KNHI reimbursement criteria more closely reflect the T2T strategy as compared with the past KNHI reimbursement criteria, as shown in Table 1. Thus, it is anticipated that the amendment of the KNHI reimbursement criteria may result in better treatment response. However, there was no significant difference in the 1-year treatment response, such as the frequency of remission and moderate-to-good EULAR response, between the past and current KNHI reimbursement criteria in our data. This unexpected result probably can be explained by the small sample size in our study, which led to the low statistical power to detect any differences between the past and current criteria. In addition, due to the retrospective design, a substantial portion of patients could not be followed-up at 1 year (Figure 1), and a significant difference in baseline disease activities between the past and current criteria was observed (Table 1 ), which can act as confounding factors for the result of our analysis. Thus, further large-scale studies are warranted to investigate whether the recent amendment of the KNHI reimbursement criteria can improve the treatment response to anti-TNF- $\alpha$ therapy.

Drug persistence can be interpreted as surrogate markers for long-term efficacy, safety, and tolerability and should be considered in real-world decision making [26-28], because lifelong treatment with DMARDs is required for patients with RA [2,3]. Thus, identifying associated factors for and promoting drug persistence are crucial for optimal care of RA patients. Given that lack of efficacy has been proposed as a major cause for discontinuation of anti-TNF- $\alpha$ therapy in previous studies $[29,30]$ and our analysis (Table 4), we supposed that changes in the maintenance criteria of the KNHI reimbursement system may be significantly associated with persistence of these medications. The agreement rate of the maintenance criteria between the past and current reimbursement criteria was reported to be low in a previous Korean study [7], which supports this hypothesis. However, the amendment of the KNHI reimbursement criteria did not have a significant impact on the long-term persistence rate of anti-TNF- $\alpha$ therapy in this study. Similar to our finding, Lee et al. [9] reported that the changes in KNHI polices, such as the introduction of the expanding benefit coverage for RA patients, did not affect the 6-month persistence rate of anti-TNF- $\alpha$ agents. Given that the determinants for drug persistence are complex and multifactorial $[16,31]$, the amendment of the KNHI reimbursement criteria alone seemed to be not sufficient to alter the overall persistence to anti-TNF- $\alpha$ agents. Given that only a limited number of RA patients in Korea were analyzed in our study, additional studies will be needed to validate our finding.

The potential limitations in the present study should be discussed. First, although this is a multicenter study, the RA patients evaluated in the current study may not be representative of all patients in Korea, and the sample size was small. To overcome this limitation, the analysis of the national claim database or large-scale registry data can be an alternative approach to investigate the clinical impact of the amendment of the national reimbursement criteria. Second, owing to its retrospective nature, some missing data were encountered during data collection in our study, which may have influenced the study results. Third, because the majority of RA patents $(71.6 \%)$ was treated with adalimumab and only $4.7 \%$ of patients received infliximab, we could not analyze the study results according to each anti-TNF- $\alpha$ agent. In particular, it has been reported that there was a significant difference in the persistence rate among anti-TNF- $\alpha$ agents $[26,29,30]$. Thus, further studies adjusting the effect of the type of anti-TNF- $\alpha$ agents are necessary.

\section{CONCLUSION}

In conclusion, although treatment response and drug persistence did not differ significantly between the past and current KNHI reimbursement criteria, the baseline disease activities in RA patients treated with anti-TNF- $\alpha$ agents under the current criteria was significantly lower 
than those treated with anti-TNF- $\alpha$ agents under the past criteria. Thus, the recent amendment of the KNHI reimbursement criteria can provide more health benefits in patients with RA and can improve the access to anti-TNF$\alpha$ agents. Our study highlights the importance of the appropriate national reimbursement criteria for anti-TNF $\alpha$ therapy considering the clinical significance of anti-TNF$\alpha$ agents in the optimal management of RA. However, owing to the small sample size and retrospective design, further investigations are obviously needed to validate our findings.

\section{ACKNOWLEDGMENTS}

We specially thank the late Professor Sung-Il Kim who devoted himself to education, research, and patient care in Division of Rheumatology, Department of Internal Medicine, Pusan National University School of Medicine (1963 to 2011). This work was supported by clinical research grant from Pusan National University Hospital in 2020.

\section{CONFLICT OF INTEREST}

No potential conflict of interest relevant to this article was reported.

\section{AUTHOR CONTRIBUTION}

Y.K.: study design, data collection and analysis and writing manuscript, G.T.K.: data interpretation and revision of manuscript, Y.S.S.: data collection and interpretation, H.O.K.: data interpretation and revision of manuscript, H.N.L.: data collection, S.G.L.: study design, data analysis and interpretation, writing manuscript and coordination of entire study.

\section{SUPPLEMENTARY DATA}

Supplementary data can be found with this article online at https://doi.org/10.4078/jrd.2020.27.3.159.

\section{REFERENCES}

1. Caporali R, Crepaldi G, Codullo V, Benaglio F, Monti S, Todoerti M, et al. 20 years of experience with tumour necrosis factor inhibitors: what have we learned? Rheumatology (Oxford) 2018;57(57 Suppl 7):vii5-10.

2. Singh JA, Saag KG, Bridges SL Jr, Akl EA, Bannuru RR,
Sullivan MC, et al. 2015 American College of Rheumatology guideline for the treatment of rheumatoid arthritis. Arthritis Rheumatol 2016;68:1-26.

3. Smolen JS, Landewé R, Bijlsma J, Burmester G, Chatzidionysiou K, Dougados M, et al. EULAR recommendations for the management of rheumatoid arthritis with synthetic and biological disease-modifying antirheumatic drugs: 2016 update. Ann Rheum Dis 2017;76: 960-77.

4. Souliotis K, Papageorgiou M, Politi A, Ioakeimidis D, Sidiropoulos P. Barriers to accessing biologic treatment for rheumatoid arthritis in Greece: the unseen impact of the fiscal crisis--the Health Outcomes Patient Environment (HOPE) study. Rheumatol Int 2014;34:25-33.

5. Desai RJ, Rao JK, Hansen RA, Fang G, Maciejewski ML, Farley JF. Predictors of treatment initiation with tumor necrosis factor- $\alpha$ inhibitors in patients with rheumatoid arthritis. J Manag Care Spec Pharm 2014;20:1110-20.

6. Son KM, Jung DM, Kim YB, Han JS, Seo YI, Jung YO, et al. Comparison Korean National Health Insurance Reimbursement and other guidelines for TNF- $\alpha$ blocker in rheumatoid arthritis. J Rheum Dis 2012;19:334-40.

7. Won S, Sung YK, Cho SK, Choi CB, Koh EM, Kim SK, et al. Prediction for TNF inhibitor users in RA patients according to reimbursement criteria based on DAS28. J Rheum Dis 2014;21:64-73.

8. Lee YJ. Usage of Anti-TNF $\alpha$ agents in patients with rheumatoid arthritis and Korean National Health Insurance reimbursement criteria. J Rheum Dis 2014;21:107-9.

9. Lee JH, Cho SK, Choi CB, Sung YK, Bae SC. Impact of change in reimbursement guideline of rheumatoid arthritis on the short term persistence of Tumor Necrosis Factor (TNF) blockers. J Rheum Dis 2011;18:283-7.

10. Arnett FC, Edworthy SM, Bloch DA, McShane DJ, Fries JF, Cooper NS, et al. The American Rheumatism Association 1987 revised criteria for the classification of rheumatoid arthritis. Arthritis Rheum 1988;31:315-24.

11. Aletaha D, Neogi T, Silman AJ, Funovits J, Felson DT, Bingham CO 3rd, et al. 2010 Rheumatoid arthritis classification criteria: an American College of Rheumatology/ European League Against Rheumatism collaborative initiative. Arthritis Rheum 2010;62:2569-81.

12. Prevoo ML, van 't Hof MA, Kuper HH, van Leeuwen MA, van de Putte LB, van Riel PL. Modified disease activity scores that include twenty-eight-joint counts. Development and validation in a prospective longitudinal study of patients with rheumatoid arthritis. Arthritis Rheum 1995;38:44-8.

13. van Riel PL. The development of the disease activity score (DAS) and the disease activity score using 28 joint counts (DAS28). Clin Exp Rheumatol 2014;32(5 Suppl 85):S-6574.

14. van Gestel AM, Prevoo ML, van't Hof MA, van Rijswijk MH, van de Putte LB, van Riel PL. Development and validation of the European League Against Rheumatism response criteria for rheumatoid arthritis. Comparison with the preliminary American College of Rheumatology and the World Health Organization/International League Against Rheumatism Criteria. Arthritis Rheum 1996;39:34-40.

15. Lee HN, Kim YK, Kim GT, Ahn E, So MW, Sohn DH, et al. Neutrophil-to-lymphocyte and platelet-to-lymphocyte ratio as predictors of 12-week treatment response and drug per- 
sistence of anti-tumor necrosis factor- $\alpha$ agents in patients with rheumatoid arthritis: a retrospective chart review analysis. Rheumatol Int 2019;39:859-68.

16. Park JH, Park EK, Koo DW, Lee S, Lee SH, Kim GT, et al. Compliance and persistence with oral bisphosphonates for the treatment of osteoporosis in female patients with rheumatoid arthritis. BMC Musculoskelet Disord 2017;18:152.

17. Lee SG, Park EK, Park JH, Kweon SM, Kim YK, Kim GT. Compliance and persistence with hydroxychloroquine in South Korean patients with systemic lupus erythematosus. Lupus 2018;27:753-61.

18. Orlewska E, Ancuta I, Anic B, Codrenau C, Damjanov N, Djukic P, et al. Access to biologic treatment for rheumatoid arthritis in Central and Eastern European (CEE) countries. Med Sci Monit 2011;17:SR1-13.

19. Hoebert JM, Mantel-Teeuwisse AK, van Dijk L, Bijlsma JW, Leufkens HG. Do rheumatoid arthritis patients have equal access to treatment with new medicines?: tumour necrosis factor-alpha inhibitors use in four European countries. Health Policy 2012;104:76-83.

20. Putrik P, Ramiro S, Kvien TK, Sokka T, Uhlig T, Boonen A. Variations in criteria regulating treatment with reimbursed biologic DMARDs across European countries. Are differences related to country's wealth? Ann Rheum Dis 2014;73:2010-21.

21. Putrik P, Ramiro S, Kvien TK, Sokka T, Pavlova M, Uhlig T, et al. Inequities in access to biologic and synthetic DMARDs across 46 European countries. Ann Rheum Dis 2014;73: 198-206.

22. Kaló Z, Vokó Z, Östör A, Clifton-Brown E, Vasilescu R, Battersby A, et al. Patient access to reimbursed biological disease-modifying antirheumatic drugs in the European region. J Mark Access Health Policy 2017;5:1345580.

23. Bergstra SA, Branco JC, Vega-Morales D, Salomon-Escoto $\mathrm{K}$, Govind $\mathrm{N}$, Allaart $\mathrm{CF}$, et al. Inequity in access to bDMARD care and how it influences disease outcomes across countries worldwide: results from the METEOR- registry. Ann Rheum Dis 2018;77:1413-20.

24. Hur JW, Choe JY, Kim DW, Kim HA, Kim SH, Kim WU, et al. Rheumatoid arthritis patients fulfilling Korean National Health Insurance reimbursement guidelines for anti-tumor necrosis factor- $\alpha$ treatment and comparison to other guidelines. Rheumatol Int 2015;35:1817-23.

25. Smolen JS, Breedveld FC, Burmester GR, Bykerk V, Dougados M, Emery P, et al. Treating rheumatoid arthritis to target: 2014 update of the recommendations of an international task force. Ann Rheum Dis 2016;75:3-15.

26. Neovius M, Arkema EV, Olsson H, Eriksson JK, Kristensen LE, Simard JF, et al. Drug survival on TNF inhibitors in patients with rheumatoid arthritis comparison of adalimumab, etanercept and infliximab. Ann Rheum Dis 2015; 74:354-60.

27. Park EY, Lee SG, Park EK, Koo DW, Park JH, Kim GT, et al. Drug survival and the associated predictors in South Korean patients with rheumatoid arthritis receiving tacrolimus. Korean J Intern Med 2018;33:193-202.

28. Park JA, Lee MY, Nam JH, Shin JY, Wood R, Holbrook T, et al. Real-world treatment persistence of non-tumor necrosis factor inhibitors versus tumor necrosis factor inhibitors among patients with rheumatoid arthritis in South Korea. Curr Med Res Opin 2020;36:343-51.

29. Kang JH, Park DJ, Lee JW, Lee KE, Wen L, Kim TJ, et al. Drug survival rates of tumor necrosis factor inhibitors in patients with rheumatoid arthritis and ankylosing spondylitis. J Korean Med Sci 2014;29:1205-11.

30. Favalli EG, Pregnolato F, Biggioggero M, Becciolini A, Penatti AE, Marchesoni A, et al. Twelve-year retention rate of first-line tumor necrosis factor inhibitors in rheumatoid arthritis: real-life data from a local registry. Arthritis Care Res (Hoboken) 2016;68:432-9.

31. Malaviya AP, Ostör AJ. Drug adherence to biologic DMARDS with a special emphasis on the benefits of subcutaneous abatacept. Patient Prefer Adherence 2012;6: 589-96. 